\title{
Converged Wireless and Wireline Access System Based on Optical Phase Modulation for Both Radio-Over-Fiber and Baseband Signals
}

\author{
Yu, Xianbin; Jensen, Jesper Bevensee; Zibar, Darko; Peucheret, Christophe; Tafur Monroy, Idelfonso
}

Published in:

I E E E Photonics Technology Letters

Link to article, DOI:

10.1109/LPT.2008.2004698

Publication date:

2008

Document Version

Publisher's PDF, also known as Version of record

Link back to DTU Orbit

Citation (APA):

Yu, X., Jensen, J. B., Zibar, D., Peucheret, C., \& Tafur Monroy, I. (2008). Converged Wireless and Wireline Access System Based on Optical Phase Modulation for Both Radio-Over-Fiber and Baseband Signals. I E E E Photonics Technology Letters, 20(21), 1814-1816. https://doi.org/10.1109/LPT.2008.2004698

\section{General rights}

Copyright and moral rights for the publications made accessible in the public portal are retained by the authors and/or other copyright owners and it is a condition of accessing publications that users recognise and abide by the legal requirements associated with these rights.

- Users may download and print one copy of any publication from the public portal for the purpose of private study or research.

- You may not further distribute the material or use it for any profit-making activity or commercial gain

- You may freely distribute the URL identifying the publication in the public portal 


\title{
Converged Wireless and Wireline Access System Based on Optical Phase Modulation for Both Radio-Over-Fiber and Baseband Signals
}

\author{
Xianbin Yu, Jesper Bevensee Jensen, Darko Zibar, Christophe Peucheret, and Idelfonso Tafur Monroy
}

\begin{abstract}
We propose and experimentally investigate a scheme for transmitting a phase-modulated radio-over-fiber (RoF) signal along an existing fiber infrastructure without degradation of the existing baseband signal. Optical phase encoding of both signals, namely a baseband 21.4-Gb/s nonreturn-to-zero differential quaternary phase-shift keyed signal and a 5.25-GHz RoF carrying $1.25 \mathrm{~Gb} / \mathrm{s}$, enables the use of identical optical receiver structures. The experimental results show that both receivers achieve error-free operation after $80-\mathrm{km}$ standard single-mode fiber transmission. The proposed scheme has potential applications for converged wireless and wireline optical access networks.
\end{abstract}

Index Terms-Digital signal processing (DSP), optical wireless access network, phase modulation, radio-over-fiber (RoF).

\section{INTRODUCTION}

$\mathbf{T}$ HERE is an increasing demand from broadband telecommunication end-users to have instant access to high-capacity information services, whether from a fixed or a mobile terminal. Recently, radio-over-fiber (RoF) technology has attracted more and more attention to provide wireless connectivity due to its advantages of low-transmission loss and high bandwidth of optical fibers [1], [2]. Therefore, the consolidation of RoF and high-speed baseband signals transport over a common optical infrastructure is foreseen to pave the way for a seamless broadband experience for the end-users.

Fig. 1 illustrates the scenario for a dense wavelengthdivision-multiplexing wireless/wireline converged access network. At the central office, optical high-speed digital signals are delivered for fiber-to-the-home or fixed terminals. Moreover, RoF signals are transmitted to the remote access points destined for the remote base station for wireless/wireline services. This consolidated signal transport scheme exploits both the reliability and high bandwidth of the optical fiber. Most of the previous efforts have been focused on the convergence of RoF and baseband by separating the signals in the frequency domain and employing different receivers [3], [4]. An identical receiver structure for digital and RoF signals would be very cost-effective. Moreover, a phase modulator at the RoF transmitter does not need bias control and offers better performance

Manuscript received June 02, 2008; revised July 29, 2008. First published August 22, 2008; current version published October 17, 2008.

The authors are with the DTU Fotonik, Department of Photonics Engineering, Technical University of Denmark, DK-2800 Kgs. Lygnby, Denmark (e-mail: xyu@com.dtu.dk).

Color versions of one or more of the figures in this letter are available online at http://ieeexplore.ieee.org.

Digital Object Identifier 10.1109/LPT.2008.2004698

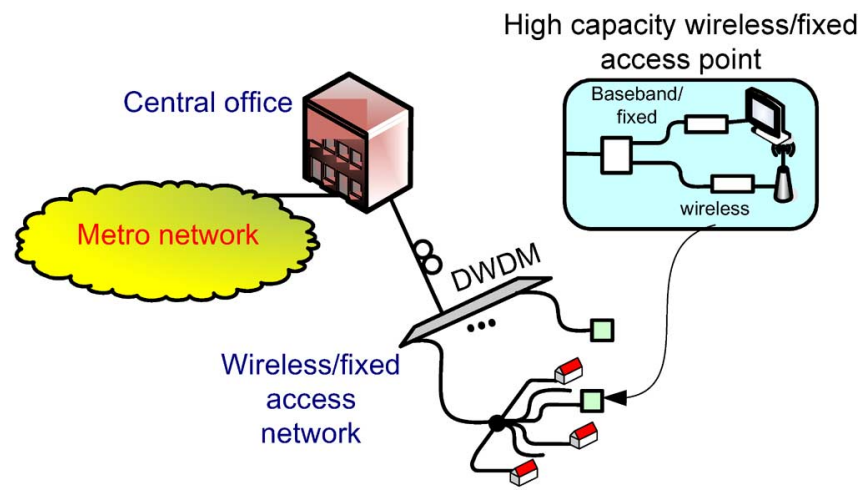

Fig. 1. Illustration of a wireless/wireline access network.

than an intensity modulator in term of linearity [5], [6], which otherwise severely limits the RoF system performance [7], [8]. Hence, a converged access system combining phase modulation RoF and high-speed baseband signals is a promising solution to provide several different services for fixed and mobile users.

In this letter, we experimentally demonstrate the feasibility of converged phase modulated RoF and baseband transmission system along a common fiber infrastructure and using the same optical receiver structure. Experimental results show that both 21.4-Gb/s nonreturn-to-zero quaternary phase-shift keyed (NRZ-DQPSK) signal and optical phase modulated $5.25-\mathrm{GHz}$ RoF carrying $1.25 \mathrm{~Gb} / \mathrm{s}$, are error free after $80-\mathrm{km}$ fiber transmission.

\section{EXPERIMENTAL SETUP}

The experimental setup is shown in Fig. 2. The RoF signal is generated by mixing an NRZ $1.25-\mathrm{Gb} / \mathrm{s}$ pseudorandom binary sequence (PRBS) with length of $2^{11}-1$ and a $5.25-\mathrm{GHz}$ radio frequency $(\mathrm{RF})$ signal. The amplitude modulated RF is used for optical phase modulation (modulation index: $0.86 \pi$ ) of a continuous-wave light from an external cavity laser with a wavelength of $1556.04 \mathrm{~nm}$. A 21.4-Gb/s NRZ-DQPSK modulation is applied to a second continuous-wave light at a wavelength of $1555.94 \mathrm{~nm}$. The NRZ-DQPSK modulation is performed by a dual Mach-Zehnder modulator driven by two decorrelated 10.7-Gb/s PRBS signals with lengths of $2^{7}-1$. The short pattern length is used due to limited programmability of the error detector. These two optical signals are combined with orthogonal polarizations in a polarizing beam splitter (PBS), and launched into a transmission span consisting of $80-\mathrm{km}$ standard single- 


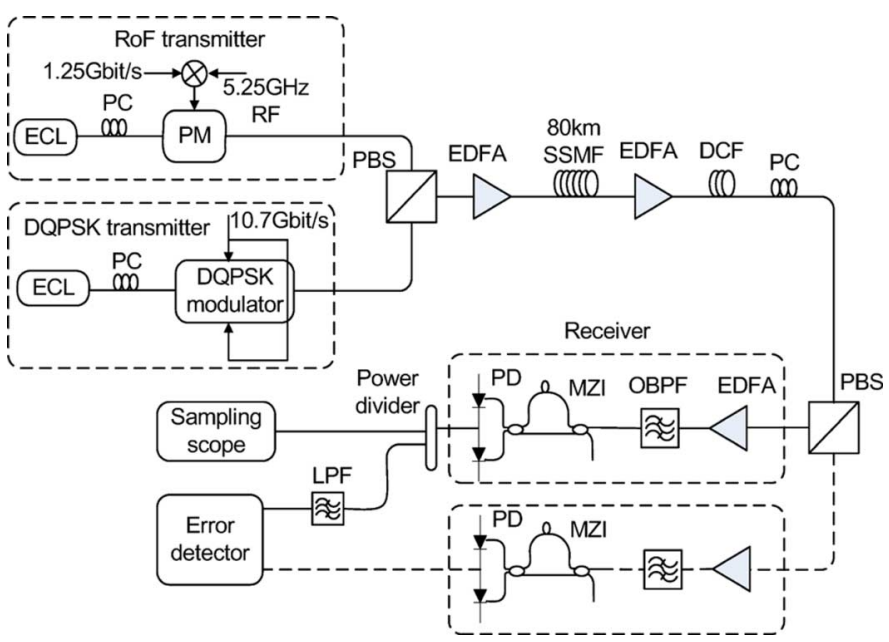

Fig. 2. Experimental setup of converged wireless and wireline system. ECL: external cavity laser; PM: phase modulator; PC: polarization controller; DCF: dispersion-compensating fiber; OBPF: optical bandpass filter; LPF: lowpass filter.

mode fiber (SSMF) and a matching length of $13-\mathrm{km}$ dispersion-compensating fiber.

At the receiver, polarization separation is performed by another PBS before detection by a preamplified receiver setup consisting of an erbium-doped fiber amplifier (EDFA), an optical bandpass filter with a 3-dB bandwidth of $0.4 \mathrm{~nm}$, a Mach-Zehnder delay interferometer (MZI) with a free spectral range of $10.7 \mathrm{GHz}$, a pair of balanced photodiodes (PDs), and an error detector. The MZI can convert both the RoF and baseband phase-encoded information into intensity information. For the reception of the NRZ-DQPSK baseband signal, the MZI is operated at quadrature points in order to demodulate one of the two DQPSK tributaries. For the reception of the optical phase-modulated RoF signal, the MZI acts as a microwave photonic filter with transfer function $H(\omega) \propto \sin ^{2}(\omega \tau / 2)$, where $\omega$ and $\tau$ are RF frequency and delay time of MZI, respectively [6]. By tuning the phase offset between the two arms of the MZI, a valley of its transfer function is made to coincide with the value of the RF carrier which, therefore, will be suppressed. In this way, the signal after photodetection is composed of both a down-converted $1.25-\mathrm{Gb} / \mathrm{s}$ baseband component and higher even order frequency components containing the complete RoF signal. Such high order components could be used to directly drive an antenna following suitable amplification if required. Therefore, by using appropriate electrical filters, the baseband down-converted signal can be directly destined to a fixed terminal and the high-order components copies of the RoF can be used to communicate with wireless users.

In a real implementation of the proposed scheme, a dynamic polarization controller before the PBS can be used to track the changing output state of polarization caused by polarizationmode dispersion. In addition, three MZIs will be required for optical demodulation: two for the in-phase and quadrature components of the NRZ-DQPSK signal and one for the RoF demodulation. In our reported experiment, only one is used, and the RoF and baseband signals are measured one after the other. Before the receiver, the signal is loaded with noise from an open-ended EDFA, and the optical signal-to-noise ratio (OSNR) is measured with an optical spectrum analyzer (noise bandwidth $=0.1 \mathrm{~nm}$ ).

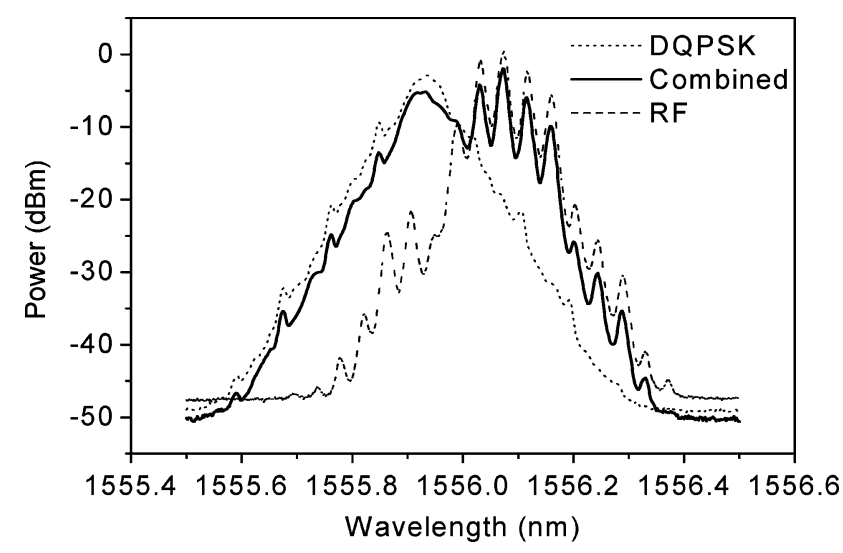

Fig. 3. Optical spectra of RoF and NRZ-DQPSK signals.

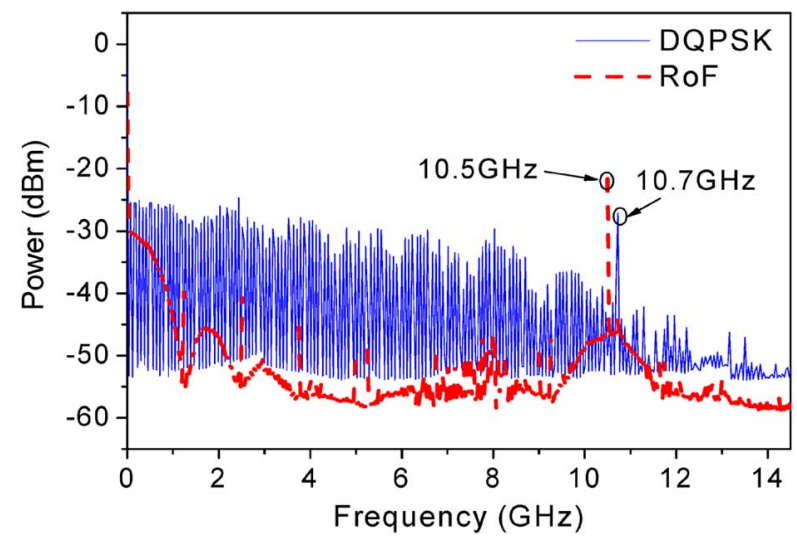

Fig. 4. Electrical spectra of RoF and NRZ-DQPSK signals.

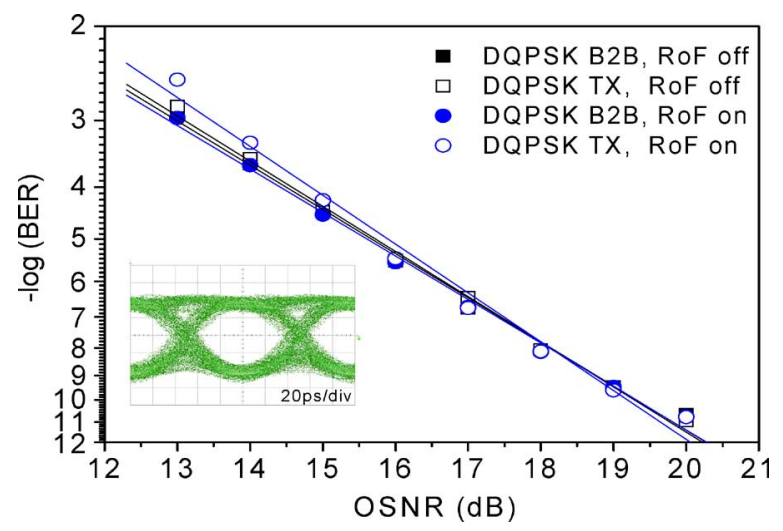

Fig. 5. BER curves of 21.4-Gb/s NRZ-DQPSK signals before and after transmission, with and without the copropagating RoF signal. B2B: back-to-back; TX: transmission.

\section{EXPERIMENTAL RESULTS}

Fig. 3 displays the optical spectra at the transmitter output when either the baseband or the RoF signals are turned on, as well as for the composite orthogonal polarization signal. The resultant electrical frequency spectra at the output of the PD are displayed in Fig. 4. In this case, the MZI offset is tuned so that the $5.25-\mathrm{GHz}$ frequency component of the RoF signal is suppressed while the down-converted baseband and second-order copy at $10.5 \mathrm{GHz}$ are dominant. Fig. 5 shows the bit-error rate (BER) before and after transmission of the $21.4-\mathrm{Gb} / \mathrm{s} \mathrm{NRZ-}$ 


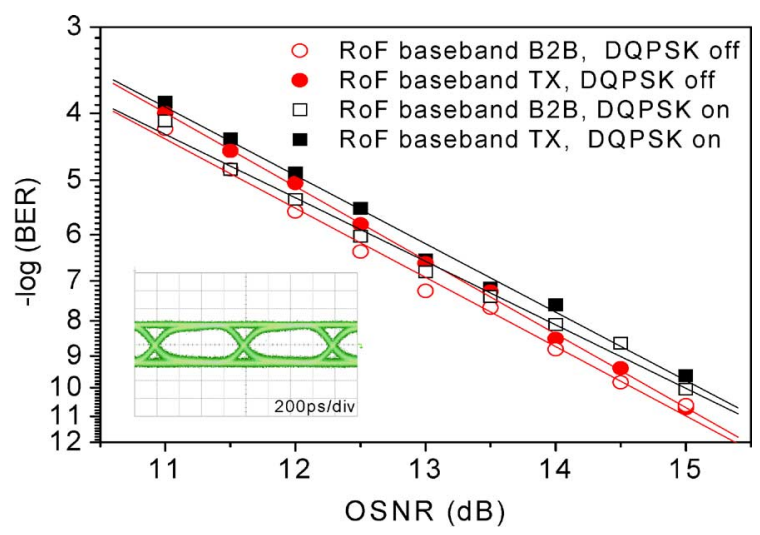

Fig. 6. BER curves of the $1.25-\mathrm{Gb} / \mathrm{s}$ RoF baseband signals before and after transmission, with and without the copropagating NRZ-DQPSK signals.

DQPSK signals with and without the RoF being present. The total BER of the NRZ-DQPSK signal is calculated as the average of the two tributaries. There is no degradation caused by the superposition of the RoF, and fiber transmission introduced no measurable power penalty. The OSNR requirement at a BER of $10^{-9}$ is $18.5 \mathrm{~dB}$ in all cases. The demodulated DQPSK eye diagram after transmission is also shown in the figure in the case the RoF is on. A clear and open eye diagram is obtained.

The measured BER for the 1.25-Gb/s RoF down-converted baseband signal before and after transmission is displayed in Fig. 6, along with the eye diagram of the demodulated signal after transmission in the presence of the DQPSK. The measured BER with, as well as without the DQPSK baseband signal, is presented. The required OSNR for a BER of $10^{-9}$ is 14.0 $\mathrm{dB}$ without the DQPSK signal and $14.6 \mathrm{~dB}$ with the DQPSK signal, corresponding to a receiver sensitivity penalty of $0.6 \mathrm{~dB}$. In both cases, fiber transmission induced no observable BER performance degradation of the signals, which is confirmed by the clear and open eye diagram.

For the 10.5-GHz wireless component, a real-time digital oscilloscope with sample rate of $40 \mathrm{GSample/s}$ is used to record signal samples for further off-line processing. The BER is obtained by using digital signal processing (DSP), which emulated the functionality of RF mixing and low-pass filtering. A low-pass filter with 1-GHz cut-off frequency is used in this case. The BER is evaluated based on Gaussian statistics on the processed 10.5-GHz signal. Even though this Gaussian model is known to suffer from limitations [9], it nevertheless enables a reasonable estimate of the OSNR penalty and therefore checks the feasibility of the scheme. As shown in Fig. 7, the DSP results indicate that the OSNR requirements at a BER of $10^{-9}$ are $17.5 \mathrm{~dB}$ after transmission and $16.5 \mathrm{~dB}$ back-to-back. All cases shown in Fig. 7 are analyzed for the case of a copropagating RoF signal with a DQPSK baseband signal.

\section{CONCLUSION}

We have proposed and experimentally demonstrated a promising scheme for consolidating transmission of a phase modulated RoF along an existing fiber infrastructure co-existing

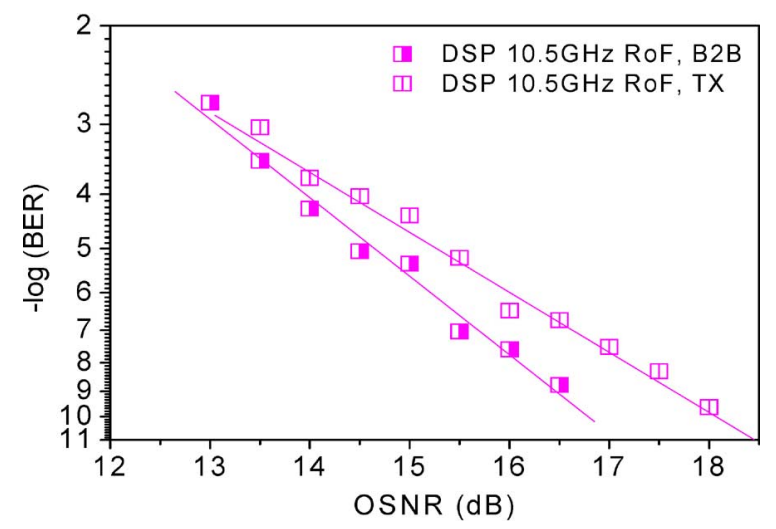

Fig. 7. BER curves of the RoF 10.5-GHz signals before and after transmission using DSP offline processing.

with a DQPSK baseband signal. By employing an MZI optical demodulator, both down-converted baseband and high-frequency copies of the RoF are obtained, which can be used to provide services for fixed and wireless users, respectively. In our experiment, phase modulation of a 5.25-GHz carrier with $1.25 \mathrm{~Gb} / \mathrm{s}$ is used for the RoF and 21.4-Gb/s NRZ-DQPSK for the baseband signal. These two signals are combined with orthogonal polarizations, transmitted over $80-\mathrm{km}$ SSMF, and detected error-free. The use of optical phase modulation allows identical optical demodulation structures to be employed for both the RoF and the baseband signals. These advantageous features make the proposed scheme of interest for applications in future consolidated wireless and wireline optical access networks.

\section{REFERENCES}

[1] A. J. Seeds and K. J. Williams, "Microwave photonics," J. Lightw. Technol., vol. 24, no. 12, pp. 4628-4641, Dec. 2006.

[2] M. Sauer, A. Kobyakov, and J. George, "Radio-over-fiber for picocellular network architectures," J. Lightw. Technol., vol. 25, no. 11, pp. 3301-3320, Nov. 2007.

[3] K. Ikeda, T. Kuri, and K. I. Kitayama, "Simultaneous three-band modulation and fiber-optic transmission of $2.5-\mathrm{Gb} / \mathrm{s}$ baseband, microwave-, and 60-GHz-band signals on a single wavelength," J. Lightw. Technol., vol. 21, no. 12, pp. 3194-3202, Dec. 2003.

[4] K. Prince and I. T. Monroy, "Converged fixed and radio-over-fiber link employing optical envelope detection and optically injected DFB laser," presented at the OFC2008, San Diego, CA, Paper OThD7.

[5] H. F. Chou, A. Ramaswamy, D. Zibar, L. A. Johansson, J. E. Bowers, M. Rodwell, and L. A. Coldren, "High linearity coherent receiver with feedback," IEEE Photon. Technol. Lett., vol. 19, no. 12, pp. 940-942, Jun. 15, 2007.

[6] V. J. Urick, F. Bucholtz, P. S. Devgan, J. D. Micknney, and K. J. Willams, "Phase modulation with interferometric detection as an alternative to intensity modulation with direct detection for analog-photonic links," IEEE Trans. Microw. Theory Tech., vol. 55, no. 9, pp. 1978-1985, Sep. 2007.

[7] C. H. Cox, E. I. Ackerman, G. E. Betts, and J. L. Prince, "Limits on the performance of RF-over-fiber links and their impacts on device design," IEEE Trans. Microw. Theory Tech., vol. 54, no. 2, pt. 2, pp. 906-920, Feb. 2006.

[8] T. E. Darcie and J. Zhang, "High performance microwave photonic links," in 2008 IEEE Radio and Wireless Symp., 2008, pp. 125-128.

[9] G. Bosco and P. Poggiolini, "On the Q factor inaccuracy in the performance analysis of optical direct-detection DPSK systems," IEEE Photon. Technol. Lett., vol. 16, no. 2, pp. 665-667, Feb. 2004. 